\title{
PCB exposure and regeneration in crinoids (Echinodermata)
}

\author{
M. Daniela Candia Carnevali ${ }^{1, *}$, Francesco Bonasoro ${ }^{1}$, Marco Patruno ${ }^{2}$, \\ Michael C. Thorndyke ${ }^{2}$, Silvana Galassi ${ }^{3}$
}

\author{
${ }^{1}$ Dipartimento di Biologia, Universita' degli Studi di Milano, via Celoria 26, 20133 Milano, Italy \\ ${ }^{2}$ School of Biological Sciences, Royal Holloway, University of London, Egham, Surrey TW20 0EX, United Kingdom \\ ${ }^{3}$ Department of Biotechnology \& Biosciences, University of Milano-Bicocca, Piazza della Scienza 2, 20126 Milano, Italy
}

\begin{abstract}
Echinoderm regeneration provides a convenient and tractable test to monitor the effects of persistent micropollutants on the developmental physiology of marine animals. Regeneration involves crucial and sensitive biological processes (cell proliferation, morphogenesis, differentiation, tissue renewal) that make it an ideal tool to assess micropollutants at the tissue and cellular level. Our results provide evidence that the regenerative response in the crinoid Antedon mediterranea is especially sensitive to PCBs and that exposure to these chemicals induces significant variations in timing and modality of arm regeneration. Prolonged exposure to low concentrations of Aroclor ${ }^{\circledR} 1260$ (14 ng $\mathrm{l}^{-1}$ of total PCBs), typical of moderately polluted coastal zones, results in abnormal arm growth in terms of both gross morphology and microscopic anatomy. In terms of tissue/cellular aspects the main modifications are: accelerated growth of the regenerate; massive cell migration/proliferation; hypertrophic development of the coelomic canals; and, extensive rearrangement of differentiated tissues of the stump. The anomalies observed in the developmental regenerative processes appear to be compatible with a pattern of pseudo-endocrine activities.
\end{abstract}

KEY WORDS: Regeneration · Echinoderms $\cdot$ PCBs $\cdot$ Bioaccumulation $\cdot$ Endocrine disrupters Resale or republication not permitted without written consent of the publisher

\section{INTRODUCTION}

Polychlorinated biphenyls (PCBs) are commercial products widely used as heat transfer fluids, hydraulic fluids, flame retardants and dielectric fluids because of their unique properties, which include resistance to biological and chemical oxidation, and nonflammability. The widespread use of PCBs, coupled with improper disposal, has led to significant contamination in developed countries and, more recently, to global pollution (Wania \& MacKay 1993, Galassi et al. 1997). These persistent and ubiquitous micropollutants are well known for affecting the natural environment because of their bio-accumulation in organisms, and they are popularly called 'gender bender' chemicals due to their typical effects as 'endocrine disrupters'

\footnotetext{
*E-mail: cndmdn@mailserver.unimi.it
}

(EDs) (Colborn \& Clement 1992, Fairley et al. 1996, Gray et al. 1996). In this respect they interfere synergistically or antagonistically with steroid hormone activity/metabolism and interact with members of the nuclear receptor family, inducing dramatic effects on gene expression, reproductive competence and growth (Cooper \& Kavlock 1997, Gillesby \& Zacharewki 1998).

Exposure to PCBs has been clearly linked to developmental/reproductive toxicity in humans, primates, rodents, mink, fish, and other wildlife species (Golub et al. 1991, Gould et al. 1997). As PCBs and many other EDs are only slowly metabolized, they tend to be persistent in organisms and can have delayed effects. Although the toxic action of PCBs is usually related to an inhibitory effect on growth (Marks et al. 1989), stimulatory effects of these chemicals at low doses on growth have also been reported in some animal models (e.g. chicken embryos, Gould et al. 1997). 
Organisms are more sensitive during development than during adulthood because these periods of increased cell division, morphogenesis and differentiation make cells more vulnerable and prone to damage. Regenerating organisms, which reproduce in the adult developmental stages, represent possible bioindicators for pollutant-induced stress at the whole organism, cellular and molecular levels. It is very probable that exposure to PCB contamination can induce variations in times and mechanisms in the physiology of regenerative development. Many echinoderms are benthic animals that are particularly susceptible to the presence of micropollutants stored in marine sediments, including PCBs (den Besten et al. 1989, Anderson et al. 1994, Schweitzer et al. 1997). They therefore offer a wide range of models for studying regenerative developmental processes (Thorndyke et al. 1999) and assessing the growth-disrupting activity of PCBs. There is good evidence that vertebrate-type steroids can be synthesized in echinoderms and that a number of physiological phenomena related to sexual and asexual reproduction, growth, development and even defence strategies can be regulated and mediated by a combination of endocrine mechanisms analogous to those seen in vertebrates (Shoenmarkers 1979, 1980, Shirai \& Walker 1988, Voogt et al. 1990, 1991, Aminin et al. 1995, Marsh \& Walker 1995, Shubina et al. 1998). A cytochrome P450 monooxygenase system present in echinoderms is involved in both the metabolism of endogenous substrates, such as steroids, and of xenobiotics (Meyer \& Bakke 1977, Landrum \& Crosby 1981, Malins \& Roubal 1982, den Besten et al. 1991, Mercier et al. 1994, den Besten 1998). In some classes (sea stars, sea urchins), long-term exposure to PCBs results in a general disturbance of steroid metabolism (i.e. lowered levels of steroids) with possible negative consequences for reproductive success and development (Voogt et al. 1984, den Besten et al. 1989, 1990a,b, 1991, Schweitzer et al. 1997, den Besten 1998). While there is considerable published evidence that PCBs can affect steroid metabolism in both larvae and adults, the specific mechanisms of action and interference with hormone regulation have not yet been explored.

The aim of the present paper is to show the impact of PCB exposure on regeneration and to assess the validity of the regenerative response for bioassay. Developmental processes in echinoderms are typically regulated by endocrine and neurohumoral mechanisms (Thorndyke \& Candia Carnevali 2001) and are potentially susceptible to interference by ED contaminants. We used the feather star Antedon mediterranea, a typical microsuspension-feeding animal on which persistent sediment-bound micropollutants could have an immediate impact. Filter-feeding species accumulate chemicals at high levels (den Besten et al. 1990a,b).
This phenomenon in A. mediterranea can be particularly relevant not only following ingestion but also via uptake through the widely exposed and unprotected ambulacral epithelium. This species can be maintained in the laboratory for many months and is particularly amenable for the experimental study of regeneration. It is characterised by a frequent and spontaneous arm autotomy followed by prompt and complete regeneration of the arm (Reichensperger 1912, Clark 1921). Arm regeneration in A. mediterranea involves an epimorphic blastemal process which has been extensively investigated and reconstructed in detail, particularly with respect to its cellular and molecular aspects (Candia Carnevali et al. 1993, 1995, 1996, 1997, 1998). For this reason it provides an ideal experimental model to test tissue and cellular dysfunctions related to regenerative development and growth (Candia Carnevali et al. 1999). Microscopic analysis allows the examination of specific target organs and cells in situ and is the most rapid method to detect adverse and chronic effects in various cells, tissues and organs (Hinton 1997). Tests were carried out in the laboratory under controlled conditions and at contamination levels similar to those of polluted Mediterranean coastal zones (Geyer et al. 1994) but lower than in heavily contaminated areas (Lake et al. 1995).

\section{MATERIALS AND METHODS}

Exposure experiments. Antedon mediterranea were collected by Scuba divers from the Gulf of Taranto and maintained in aquaria at $14^{\circ} \mathrm{C}$ on a diet of Chlorella sp. and Tetraselmis sp. Exposure to PCBs was performed in static conditions by employing a commercial mixture of Aroclor ${ }^{\circledR} 1260$. Glass aquaria (70 l) provided with an internal circulation system exchanging oxygen between overlying air and water were used both for the PCB exposure test and for controls without PCB. Aquaria were filled with $50 \mathrm{l}$ of artificial seawater and covered by glass sheets. An aqueous solution of Arochlor ${ }^{\circledR} 1260$ was prepared by adding a small volume of concentrated $n$-hexane solution to a large volume of water and then evaporating the $n$-hexane under reduced pressure. The final concentration in water was determined by GC-ECD analysis after extraction by $n$-hexane (see 'Chemical analysis'). A $100 \mathrm{ml}$ sub-sample of this concentrated solution $\left(312 \mu \mathrm{g} \mathrm{l}^{-1}\right)$ was added to the exposure aquarium $24 \mathrm{~h}$ before introducing the crinoids.

Three independent sets of experiments were carried out with individuals collected at different times of the year under similar experimental conditions. The first experiment lasted $7 \mathrm{~d}$; the second and the third lasted $14 \mathrm{~d}$. Water concentration was monitored at fixed regular intervals. 
Twenty specimens of Antedon mediterranea were employed for each set of experiments in both exposure tests and controls (20 exposed regenerating individuals; 20 control regenerating individuals). Regeneration was induced following the natural strategies as far as possible, i.e. amputating the arm at the level of the autotomy plane (for details see Candia Carnevali et al. 1993). Three arms were removed from each experimental animal immediately before introducing the specimens in the respective aquaria. Regenerating samples were collected at 1, 3, 7, and $14 \mathrm{~d}$ post amputation (pa). Percentage mortality of the organisms was very low (1 to $2 \%$ ) and was similar in both the exposed and the control samples.

Chemical analysis. Whole animals were employed for PCB determination. Three specimens were analysed for each regeneration stage. Once the regenerating arm tips were removed for biological analysis (see below), the same individuals were used for chemical analysis. These specimens were collected after 1 and $7 \mathrm{~d}$ in Expt 1, after 3, 7, and $14 \mathrm{~d}$ in Expt 2, and after 1, 3, 7 and $14 \mathrm{~d}$ in Expt 3. Control animals were sampled at the beginning and at the end of the exposure period.

Samples were stored frozen and then the whole animals for each stage were homogenised all together and lyophilised. Freeze-dried samples were extracted by acetone-hexane (1:1) in a Soxhlet apparatus and lipid content was determined by weight after solvent evaporation.

Lipids were suspended in $2 \mathrm{ml}$ of $n$-hexane and digested with concentrated $\mathrm{H}_{2} \mathrm{SO}_{4}$. PCBs were recovered by hexane. The hexane extracts were purified on a Florisil column $(4 \times 0.7 \mathrm{~cm})$ and analysed by a gas chromatograph equipped with an electron capture detector (GC-ECD) as described in Provini \& Galassi (1999).

The PCB congener concentrations in exposure water samples were determined after $n$-hexane extraction (10:1, v:v).

Biological analysis. The regenerating arms sampled were analysed by light microscope (SM, stereomicroscope, and LM, standard light microscope) and electron microscope (TEM, trasmission electron microscope, and SEM, scanning electron microscope) as described in detail in previous papers (see Candia Carnevali et al. 1993). Additional methods were used for monitoring cell proliferation, employing 5-bromodeoxyuridine (BrdU) and related immunocytochemistry (ICC) protocols (Candia Carnevali et al. 1995, 1997, 1998), and other ICC methods were used for detecting specific molecules.

Standard light microscopy and transmission electron microscopy: Exposed and control regenerating arms were prefixed with $2 \%$ glutaraldehyde in $0.1 \mathrm{M}$ cacodylate buffer for 4 to $5 \mathrm{~h}$, then, after overnight washing in the same buffer, postfixed with $1 \%$ osmium tetroxide in the same buffer. After standard dehydra- tion in an ethanol series, the samples were embedded in Epon-Araldite 812. The semithin and thin sections were cut with a Reichert Ultracut E diamond knife, stained by conventional methods (crystal violet-basic fuchsin for LM; uranyl acetate and lead citrate for TEM) and then observed in a Jenaval light microscope and Jeol 100 SX electron microscope respectively.

Immunocytochemistry (ICC): The samples were fixed in paraformaldehyde $4 \%$ / glutaraldehyde $0.1 \%$ in $0.1 \mathrm{M}$ phosphate buffer for $2 \mathrm{~h}$. Following an overnight wash in the same buffer, the samples were dehydrated and embedded in Epon-Araldite (see above). This fixation and embedding protocol maintains good tissue integrity and provides good preservation of antigenicity (see Candia Carnevali et al. 1995, 1997). It also allows preparation of both semithin sections for LM and of ultrathin sections for TEM. Semithin sagittal sections cut with LKB Ultratome V and Reichert Ultracut E were processed for immunocytochemistry (see below).

BrdU labelling: Cell proliferation was monitored by in vivo incorporation of the substituted nucleotide, BrdU, then later revealed by a monoclonal antibody against BrdU (Cell Proliferation Kit, Amersham). Individuals were immersed in BrdU dissolved in artificial seawater at a final concentration of $0.05 \%$ for the final $2 \mathrm{~h}$ of the prefixed regeneration periods. This incubation protocol allowed detection of cells actively proliferating immediately before fixation (Candia Carnevali et al. 1995, 1997). The standard BrdU-immunocytochemistry protocol for paraffin sections was modified for use with semi-thin Epon-Araldite sections, as described in detail elsewhere (Candia Carnevali et al. 1995, 1997). After brief treatment ( $2 \mathrm{~min}$ ) with a resin-remover mixture (methanol, propylene oxide and $\mathrm{KOH}$ ), the sections were rinsed with methanol, then with phosphatebuffered saline (PBS) and incubated overnight at $4^{\circ} \mathrm{C}$ with anti-BrdU serum diluted 1:100 with nuclease. Pretreatment for $20 \mathrm{~min}$ with $0.3 \% \mathrm{H}_{2} \mathrm{O}_{2}$ in PBS was performed to exclude the activity of endogenous peroxidases. After several washes in PBS the specimens were incubated for $3 \mathrm{~h}$ with peroxidase anti-mouse IgG at room temperature and, after a further wash in PBS, incubated for 5 min with $0.05 \%$ 3, 3'-diaminobenzidine and $0.03 \% \mathrm{H}_{2} \mathrm{O}_{2}$ in $\mathrm{PBS}$, and then washed in distilled water. To amplify the peroxidase reaction product, the experiments included use of the cobalt and nickel intensifier supplied with the kit. Control reactions were carried out by omitting the primary antiserum.

Cytochrome $\mathbf{P 4 5 0}$ labelling: ICC tests were carried out on resin sections according to the specific immunoperoxidase ABC system (Vector) or immunofluorescence methods. For Cytochrome P450 ICC commercial rabbit polyclonal antibodies (StressGen Biotechnology, Victoria, Canada) were used. ICC con- 
trols were either: (1) preabsorption with the appropriate antigen; (2) replacement of the primary antiserum with non-immune sera of the animal in which the primary was raised; or (3) omission of the primary antibody and incubation in PBS and $1 \%$ normal goat serum.

\section{RESULTS}

\section{Bioconcentration}

PCB congeners in the exposure water showed a gradual decrease of concentration during all 3 sets of experiments. In Expt 3 (i.e. the most complete and definitive test in terms of experimental parameters and collected data) the initial concentration was $77 \mathrm{ng} \mathrm{l}^{-1}$ and the final concentration was $4 \mathrm{ng} \mathrm{l}^{-1}$. The weighted mean was $14 \mathrm{ng} \mathrm{l}^{-1}$.

The concentration of individual PCBs in the exposure water and in samples of Antedon mediterranea at the different regenerative stages over $14 \mathrm{~d}$ is shown in Fig. 1a \& b, respectively. A sharp increase of all PCB congener concentrations (normalised for total lipid content) was observed in the animal tissues during the $14 \mathrm{~d}$ exposure period. The final PCB concentration in Expt 3

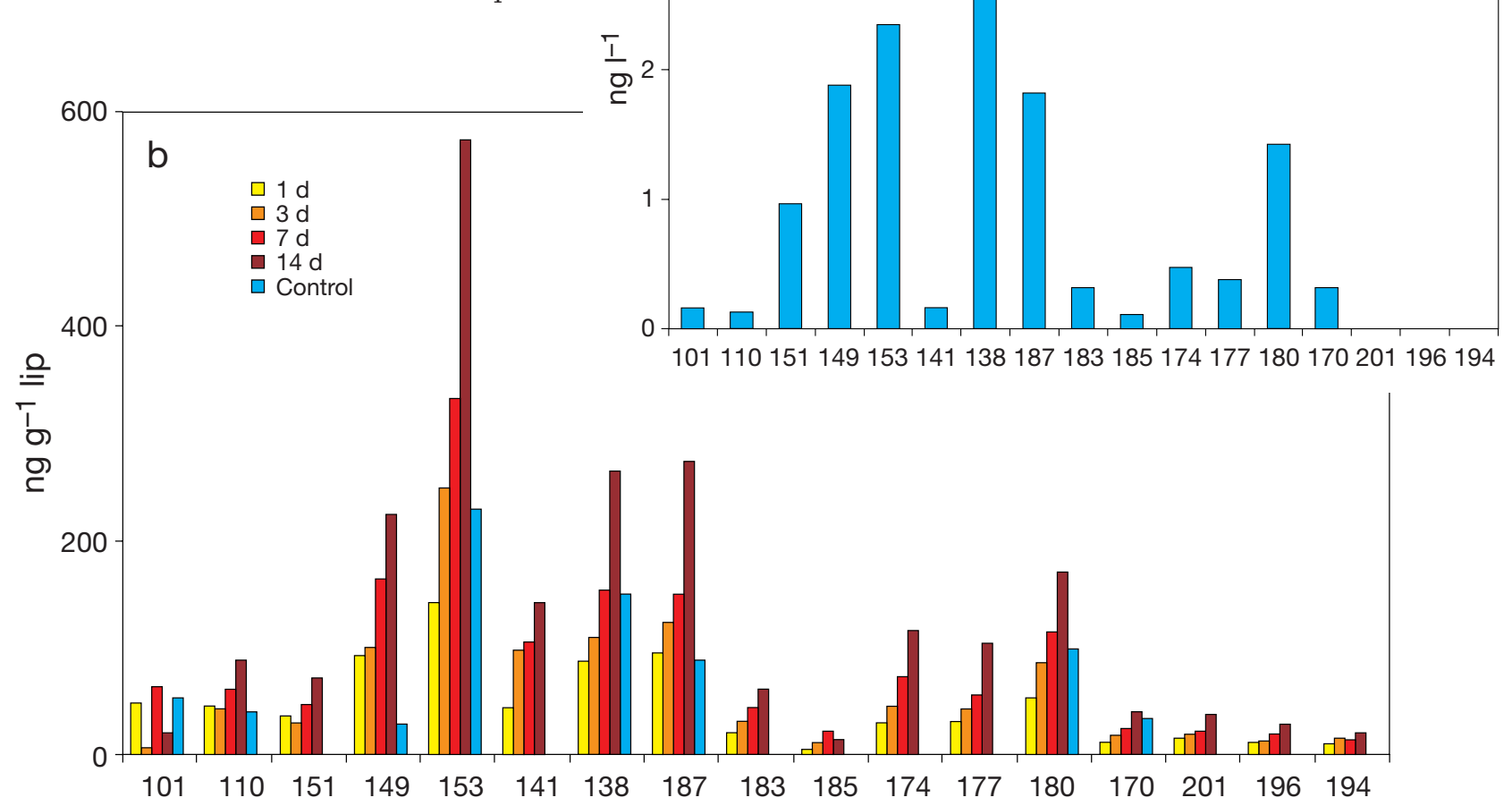

Fig. 1. PCB chemical analysis. The PCB congener trend of the commercial mixture of Aroclor ${ }^{\circledR} 1260$ employed is shown (a) for the exposure seawater, and (b) in the animal tissues, for a $14 \mathrm{~d}$ exposure during Expt 3. PCB congeners are named according to the congener numbering system adopted by Ballschmiter \& Zell (1980). The PCB congener concentrations in Antedon mediterranea (whole organism, lipid units) are given at 4 different regenerative stages $(1,3,7$ and $14 \mathrm{~d}$ ). Error bars are not given because values at each time point represent the concentration of PCB congeners (on a lipid basis) in single samples obtained by pooling tissues from 3 different individuals taken at the same stage of regeneration 

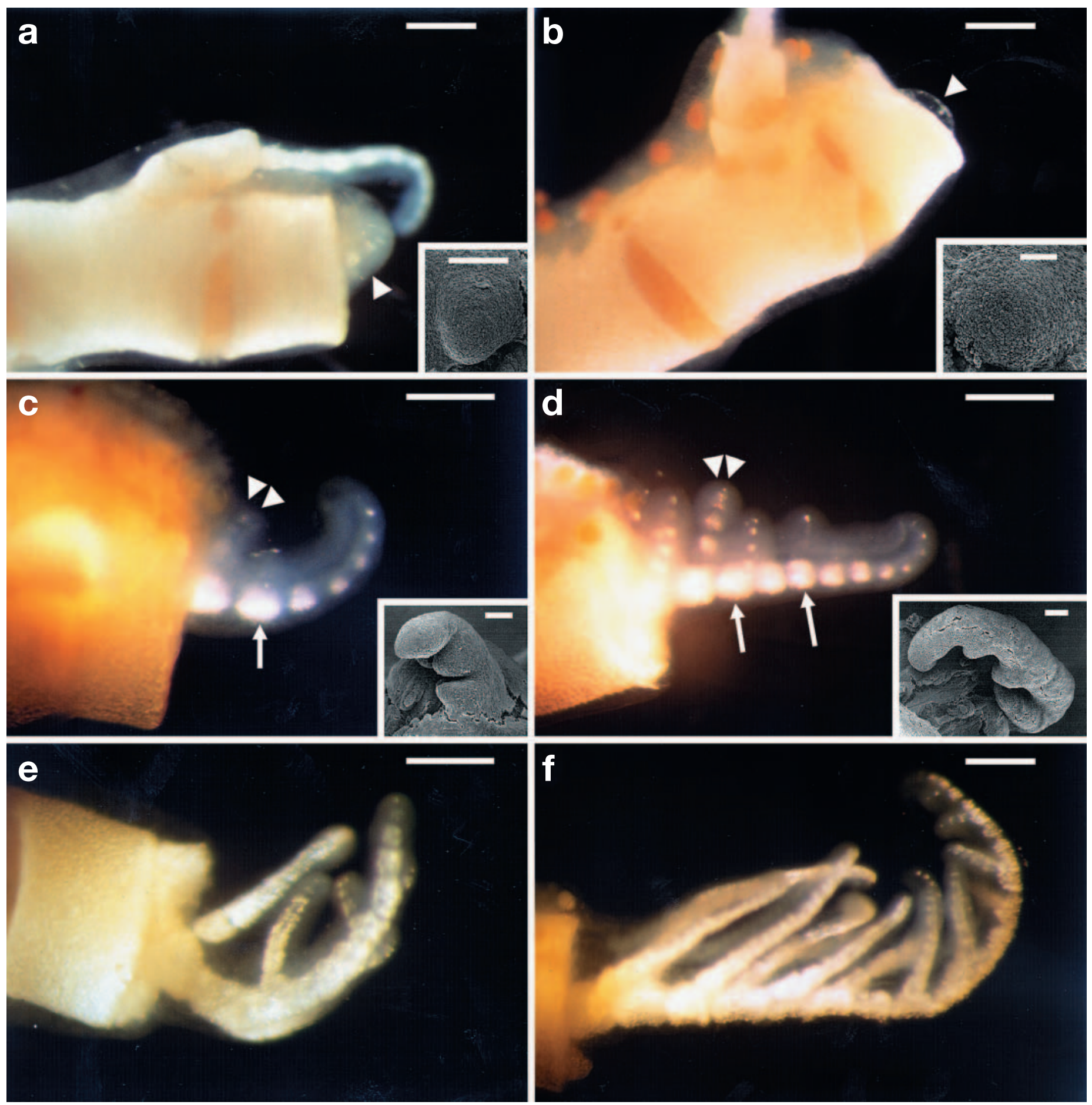

Fig. 2. Antedon mediterranea. Microscopic effects of PCB exposure on arm regeneration. (a,b) LM comprehensive views of regenerating arms at $72 \mathrm{~h}$ pa for (a) control, and (b) PCB-exposed specimens. Arrowheads points to regenerative bud. The insets show details of the regenerative blastemas under SEM. The growth of the regenerative bud is slightly delayed in the PCB-exposed sample. Scale bars $=($ a) $250 \mu$ m; (inset a)

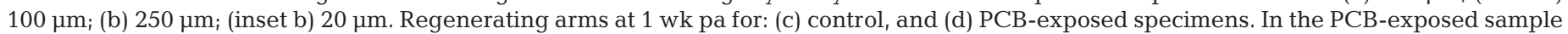
the abnormal growth of the regenerate and the advanced development of its anatomical features are evident: the arrow points to the brachial ossicles; double arrowheads point to pinnules. The insets show details of the regenerating arms under SEM. Scale bars $=(\mathrm{c}) 240 \mu \mathrm{m}$; (inset c)

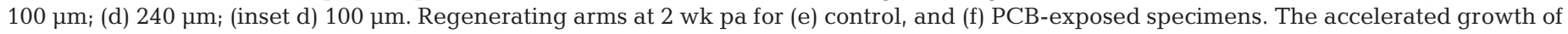
the PCB-exposed sample in comparison with the controls is impressive and can be appreciated in terms of both overall size of the regenerate and differentiation of external and internal anatomical structures. Scale bars = (e) $240 \mu \mathrm{m}$; (f) $250 \mu \mathrm{m}$ 

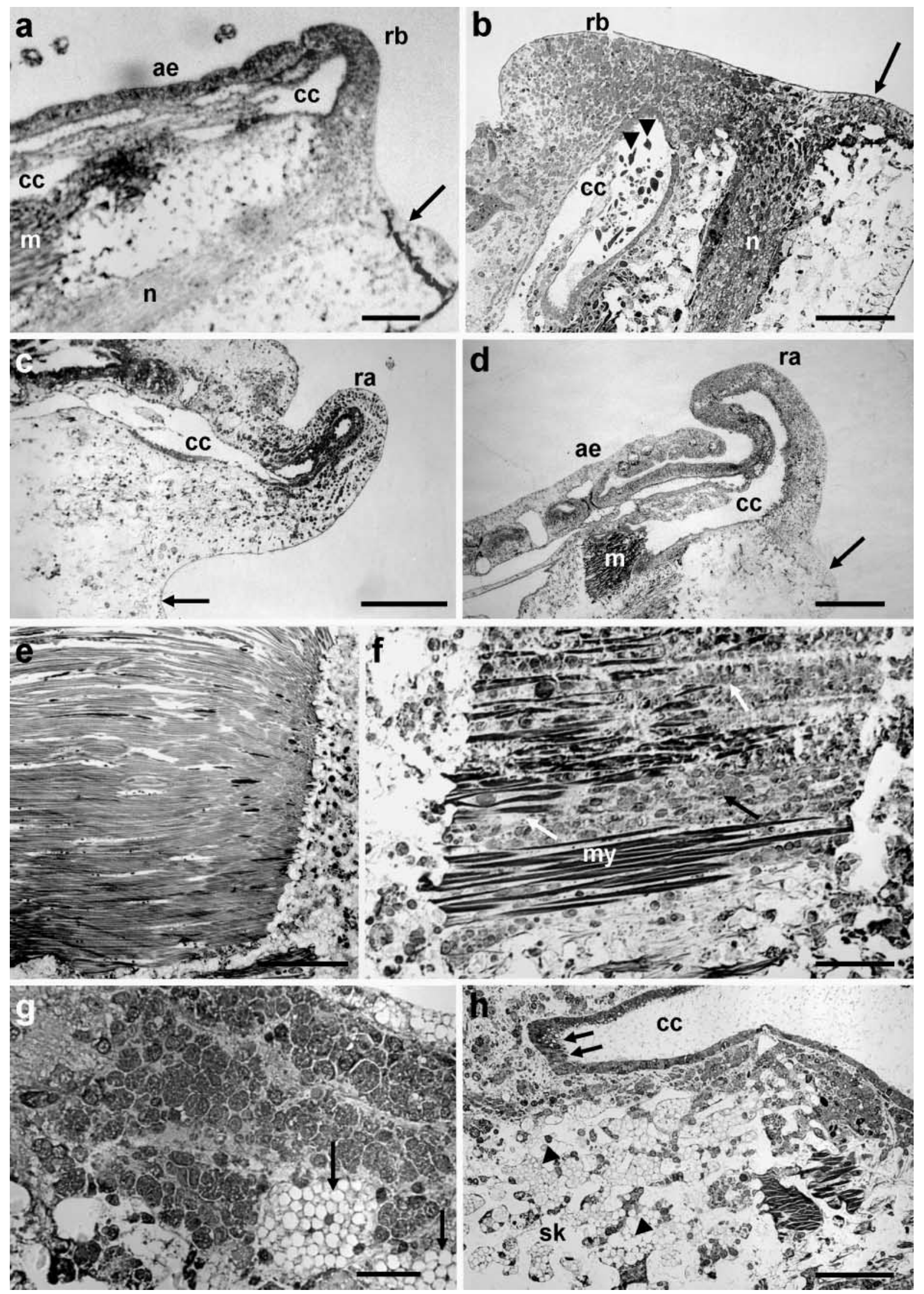
Fig. 3. Antedon mediterranea. Histological effects of PCB exposure on arm regeneration. LM sagittal sections of regenerating arms at $72 \mathrm{~h}$ pa for (a) control, and (b) PCB-exposed specimens. The PCB-exposed sample shows delayed growth of the regenerative blastema and marked hypertrophic development of the coelomic canals, which are full of migrating cells, including a num-

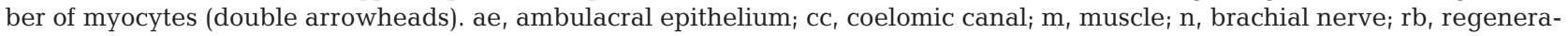
tive bud; arrow, amputation plane. Scale bars = (a) $100 \mu \mathrm{m}$; (b) $100 \mu \mathrm{m}$. LM sagittal sections of regenerating arms at $1 \mathrm{wk}$ pa for: (c) control, and (d) PCB-exposed specimens. The abnormal growth of the regenerate in the PCB-exposed sample is evident, as is

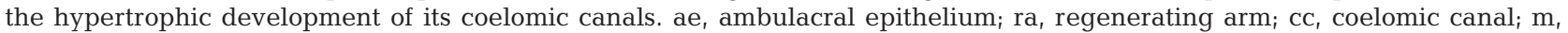
muscle; arrow, amputation plane. Scale bars = (c) $100 \mu \mathrm{m}$; (d) $200 \mu \mathrm{m}$. LM sagittal section of regenerating arms detailing the muscle bundles of the stump at $1 \mathrm{wk}$ pa for (e) control, and (f) PCB-exposed specimens. In contrast to the compact structure of the control muscle, the PCB-exposed sample shows extensive muscle rearrangement/dedifferentiation. c, coelomocytes; my, myocytes. Scale bars $=$ (e) $100 \mu \mathrm{m}$; (f) $30 \mu \mathrm{m}$. (g) LM detail in sagittal section of a PCB-exposed regenerating arm at 1 wk pa, showing a massive number of granule-cells at the level of the brachial nerve of the stump. Clear signs of vesiculation/degeneration (arrows) are detectable in the surrounding connective tissue. Scale bar $=20 \mu \mathrm{m}$. (h) LM detail in sagittal section of a PCB-exposed regenerating arm at $2 \mathrm{wk} \mathrm{pa,} \mathrm{showing} \mathrm{tissue} \mathrm{rearrangement} \mathrm{involving} \mathrm{connective} \mathrm{tissue,} \mathrm{endoskeleton} \mathrm{and} \mathrm{muscle} \mathrm{(m)} \mathrm{close} \mathrm{to} \mathrm{the} \mathrm{coelomic}$ canals (cc). Extensive vesiculation is evident at the level of both the integumental connective tissue and the endoskeletal tissue (arrowheads). Arrows, proliferation of the coelomic epithelium. Scale bar $=50 \mu \mathrm{m}$

when compared with the controls (Fig. 2a). Only a small delay in the healing of the amputation surface and in the overall growth of the regenerating blastema was evident (Fig. 2b). In contrast, at the advanced regenerative phase ( $1 \mathrm{wk} \mathrm{pa)}$ an unusual increase in growth of the regenerate was clearly evident in all the exposed arms (Fig. 2d), in comparison to the growth of the standard arms at the same stages (Fig. 2c). This accelerated growth involved the overall size of the regenerating arm, which appeared much more developed, and the differentiation of its external anatomical structures, such as the lateral pinnules, and internal structures such as the brachial ossicles (Fig. 2d). These anomalies became progressively more evident at advanced regenerative stages. At $2 \mathrm{wk}$ pa there was an impressive increase in terms of overall growth and development of anatomical features in the PCBtreated samples (Fig. 2f) in comparison to the controls (Fig. 2e). The effects at the level of general morphology could also be correlated with the appearance of relevant abnormal features in terms of microscopic anatomy in both the stump and the regenerating arm. During the repair and the early regenerative phases (up to $72 \mathrm{~h}$ pa), histological sections of PCB-exposed samples indicated clear anomalies (Fig. 3b), represented mainly by an unusual hypertrophy and swelling of the coelomic canals of both the stump and the regenerate, as well as marked cell proliferation/migration particularly at the level of the coelomic canals themselves (for a comparison with the control see Fig. 3a). It is important to emphasize that besides the employment of usual migratory elements, coelomocytes, phagocytes and granule cells (Candia Carnevali et al. 1993), the migration in the coelom also frequently involved clearly recognizable myocytes, particularly numerous in the coelomic lumen at the blastemal base (Fig. 3b). The phenomena of coelomic hypertrophy became even more evident at the advanced regenerative phase
(1 and 2 wk pa) (Fig. 3c: control; Fig. 3d: exposed sample). These samples showed that the migratory activity continued to involve a large number of cells, particularly the granule cells, whose widespread presence in the tissues at these advanced stages is very unusual and can be considered a distinctive feature of the exposed samples (Fig. 3g). The granule cells in standard conditions are extensively and specifically employed during the repair process (Candia Carnevali et al. 1993). Cell proliferation seemed to be enhanced in the exposed samples. As indicated by BrdU incorporation studies, extensive cell cycle activity was specifically localized at the level of the apical blastema and the coelomic epithelium of both the regenerate and the stump (Fig. 4a,b) from the early regenerative phase onwards. In addition, and unexpectedly, strong labelling for BrdU was also present at the level of some differentiated tissues of the stump, particularly the muscles (Fig. 4d,e). In contrast, the muscles were never labelled in the controls (Fig. 4c). In the muscles of the exposed samples, cell proliferation occurred in parallel with extensive tissue rearrangement and dedifferentiation, particularly evident in the peripherical region of the bundles (Figs. 3f \& 4e). The muscle fibres appeared to lose their usual packed and compact histological structure (Figs. 3e \& 4c) and were replaced extensively by other elements such as undifferentiated coelomocytes and phagocytes (Figs. 3f \& 4e). With TEM observation, the presence of a very heterogenous population of myocytes was clear in these bundles, characterized by different differentiation stages of their contractile apparatus, which could possibly be interpreted as progressively dedifferentiating myocytes (Fig. 4f). The active involvement of these elements in cell division was clearly indicated by BrdU labelling (Fig. 4d,e). It was significant that these processes of dedifferentiation and cell turnover at the level of the muscles were accompanied, in the adjacent coelomic canals, 

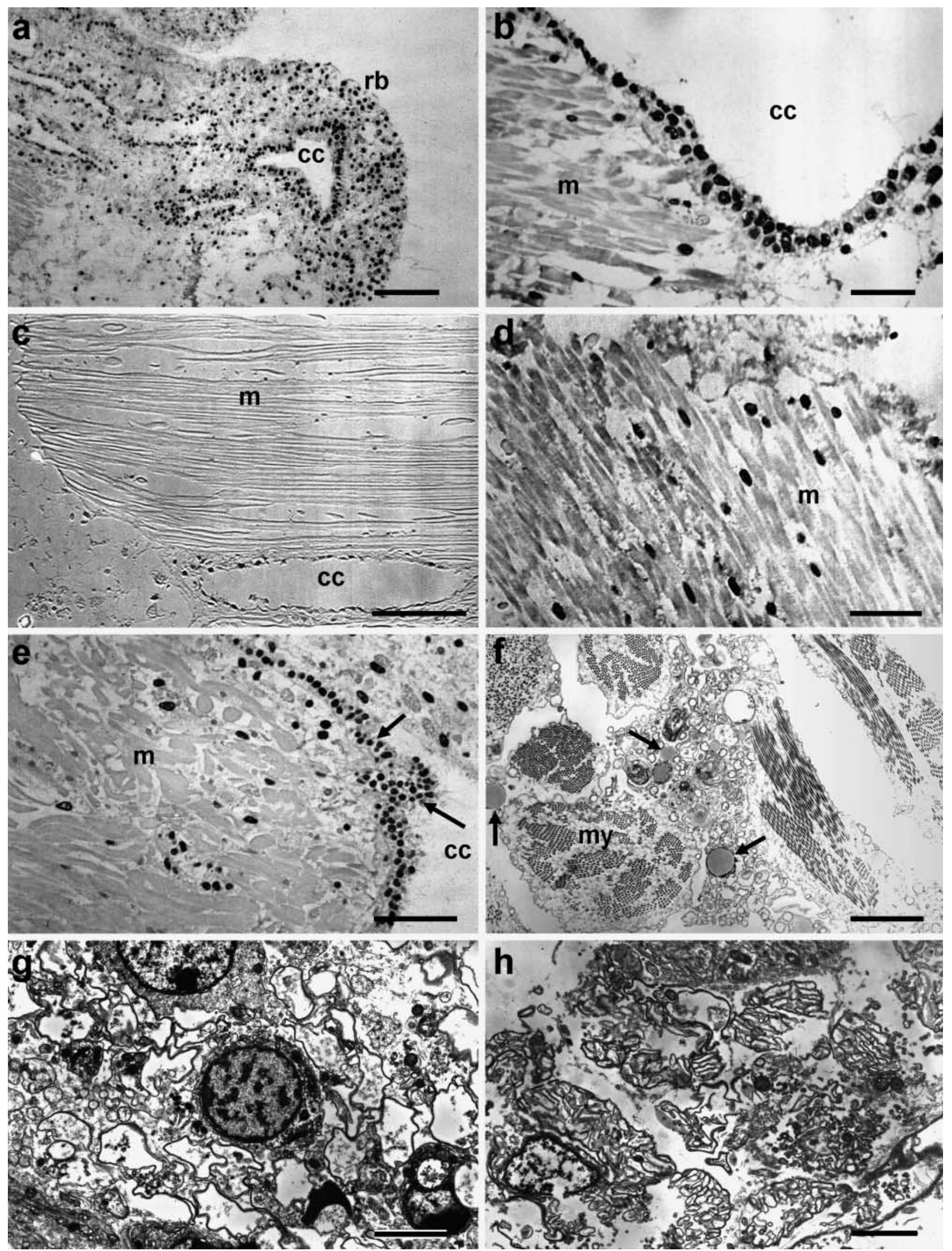

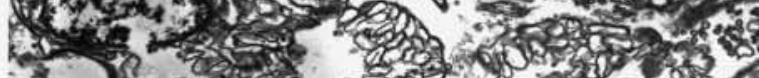
* o 050

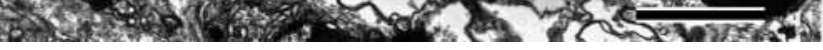


Fig. 4. Antedon mediterranea. Cellular effects of PCB exposure on arm regeneration. (a) LM sagittal sections of a PCB-exposed regenerating arm at $72 \mathrm{~h}$ pa. ICC for BrdU. Blastemal cells and the coelomic epithelium are labelled. rb, regenerative bud; CC, coelomic canal. Scale bar $=50 \mu \mathrm{m}$. (b) LM detail in sagittal sections of a PCB-exposed regenerating arm at $1 \mathrm{wk}$ pa. ICC for BrdU. The coelothelium is strongly labelled. cc, coelomic canal; $\mathrm{m}$, muscle. Scale bar $=20 \mu \mathrm{m}$. (c) LM sagittal section of a control regenerating arm of $1 \mathrm{wk}$ pa. ICC for BrdU. The immunostaining does not involve the muscle of the stump (m) but is localized at the level of the coelothelium of the coelomic canal (cc). Scale bar $=100 \mu \mathrm{m}$. (d,e) LM sagittal details of PCB-exposed regenerating arms of $1 \mathrm{wk}$ pa at the level of the stump. ICC for BrdU. Many nuclei are strongly labelled inside the muscle (m) of the stump (d), particularly in the peripheral region of the bundle where processes of muscular rearrangement are evident (e). Strong, diffuse labelling indicates extensive cell proliferation in the coelothelium of the adjacent coelomic canal (cc). Scale bars $=(\mathrm{d}) 20 \mu \mathrm{m}$; (e) $30 \mu \mathrm{m}$. (f) TEM section of a PCB-exposed sample of $1 \mathrm{wk}$ pa. Detail of muscle at the stump level. Marked dedifferentiation processes at various stages involve individual myocytes (my). Many cytoplasmic vacuoles and lipid granules (arrows) are detectable. Scale bar $=3 \mu \mathrm{m}$. (g) TEM longitudinal section of a PCB-exposed sample at $1 \mathrm{wk}$ pa. The connective tissue at the stump level is detailed, showing extensive cellular rearrangement/vacuolization, which gives rise to lace-like figures. Scale bar $=3 \mu \mathrm{m}$. (h) TEM section of a PCB-exposed sample at $2 \mathrm{wk}$ pa. The skeletal tissue is detailed at the stump level. Marked cellular vacuolization/ degeneration is detectable. Scale bar $=3 \mu \mathrm{m}$

by a massive increase in cell migration/proliferation (Figs. 3h \& 4e). The migratory elements often included, as described above, semi-dedifferentiated myocytes. This was in striking contrast to that observed in standard conditions, where regeneration was typically accomplished by employing undifferentiated stem cells, which are the elements responsible for blastema formation without any involvement of differentiated tissues of the stump (Candia Carnevali et al. 1995, 1997). In the PCB-exposed samples a certain rearrangement could also be detected in other tissues of the stump, namely the endoskeleton and the connective tissue (both integumental connective tissue and ligaments) (Fig. 3h). However, these phenomena were completely different from those seen in the muscles and were associated with an atypical cellular and extracellular pattern. At the level of both the connective and the endoskeletal tissue, tissue rearrangement mostly involved extensive degeneration phenomena (Fig. 3g,h) which led to an appreciable vacuolization/vesiculation of both the extracellular matrix and the cells (fibroblasts or scleroblasts respectively) and was characterised by the presence of lace-like remains of cell processes and membranes (Fig. 4g,h). These phenomena were always associated with a marked and unusual presence of phagocytes in the tissues. In contrast with these processes of tissue/cell turn-over localised at the stump level, at the level of the regenerating arm, the differentiation of tissues and cell lines was widely in progress (Fig. 5d,e,f). On the other hand, in the PCB exposed samples, some unusual features could be appreciated in the ultrastructural pattern of many cell types, including the blastemal cells which showed, in particular, a marked development of endoplasmic reticulum in the form of swollen cisternae of both RER, SER and Golgi complexes (Fig. 5a: control sample; Fig. 5b: PCB-exposed sample). Moreover, an unusual abundance of lipid granules and empty vacuoles appeared to be a distinctive cytological feature of all tissues in the exposed samples (Figs. 4f \& 5c,d). In addition, other results were obtained in terms of possible protective biochemical responses induced by pollutants. Our ICC experiments showed intense immunoreaction for microsomal cytochrome P-450 in the stump tissues at $1 \mathrm{wk}$ pa. It is significant that many cells appeared strongly reactive, particularly at the level of the brachial nerve (Fig. $5 \mathrm{~g}$ ), the rearranging connective tissue (Fig. $5 \mathrm{~g}$ ) and the peripheral regions of the muscle bundles (Fig. 5h).

\section{DISCUSSION}

When the exposure time is much less than the time required to establish equilibrium (Connell 1990), PCBs accumulate in animal tissues (Fig. 1). At present the equilibrium times for PCBs in echinoderms are unknown. In molluscs and fish, however, the expected equilibrium times for the less hydrophobic PCBs, which in this case are congener 101 and 110 (Hawker \& Connell 1988), should be 1 mo and 1 yr respectively (Connell 1990). Longer equilibrium times are expected for the other more hydrophobic congeners (Connell 1990). The $14 \mathrm{~d}$ total PCB concentration in Expt 3 (2257 $\mathrm{ng}$ per $\mathrm{g}$ lipid) is not far from concentrations measured in mussels and other filter feeders collected along the Mediterranean coasts (Picer \& Picer 1991, Galassi et al. 1993, Geyer et al. 1994). Interestingly, PCB concentration in the controls did not appreciably decrease during the $14 \mathrm{~d}$ period of maintenance in normal non-polluted artificial seawater: the mean value was 3 times lower than that reached by the exposed individuals at the end of the experiment, and is close to the lowest concentrations measured in mussels collected along the Mediterranean coasts (Geyer et al. 1994).

It is relevant that the PCB profile of gas chromatographic analyses apparently did not differ very much 

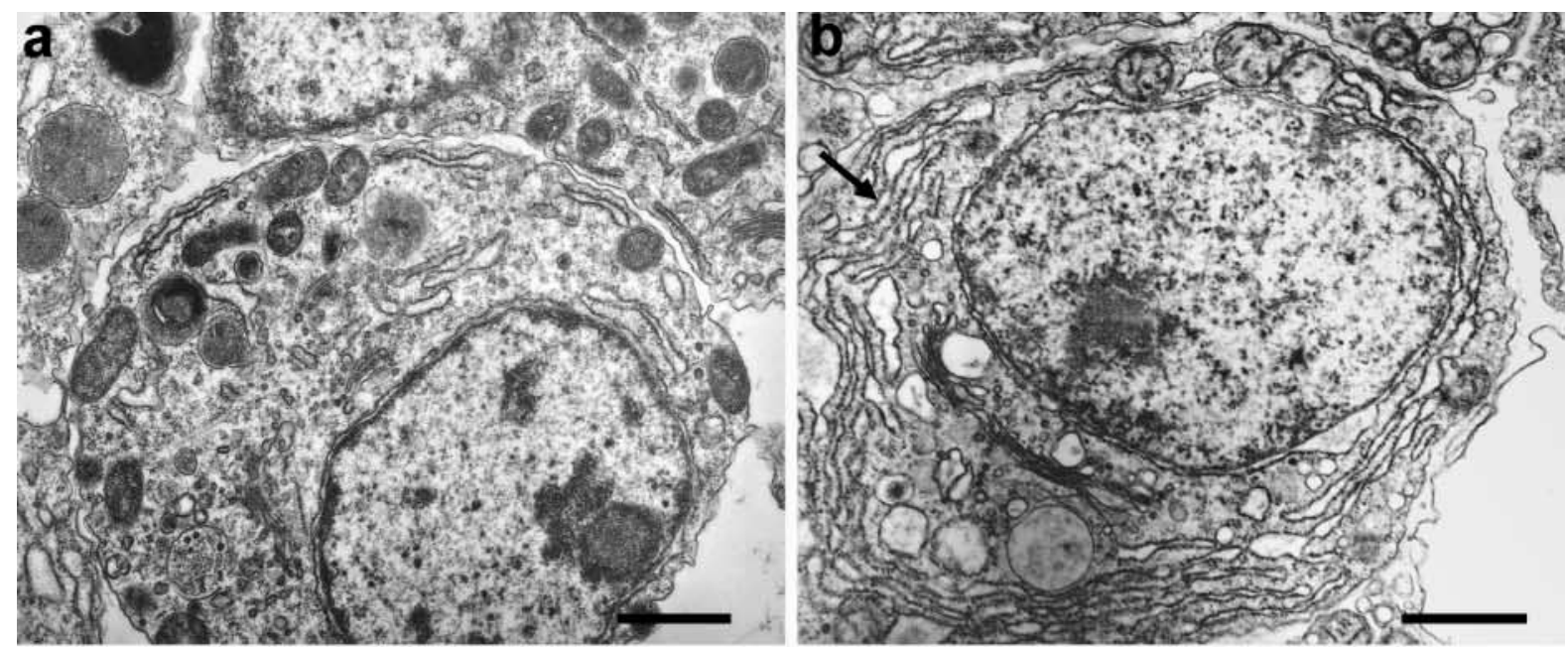

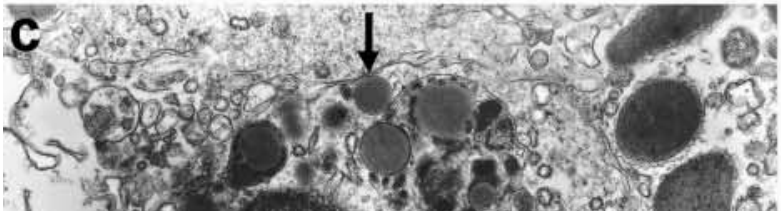
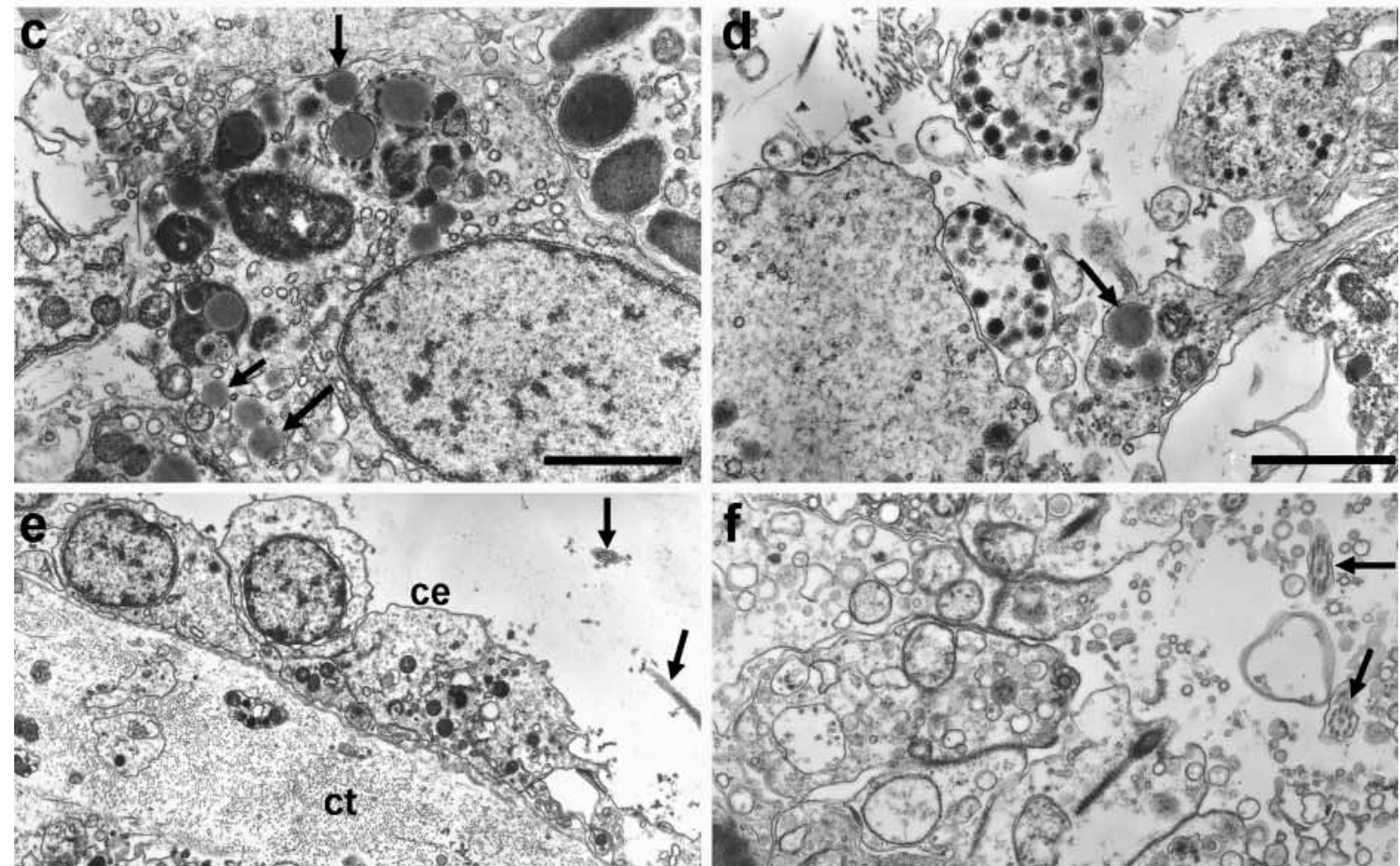

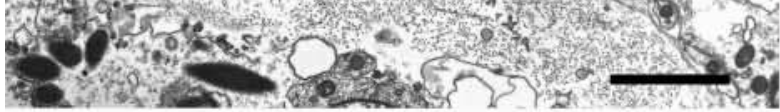

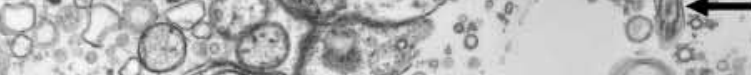

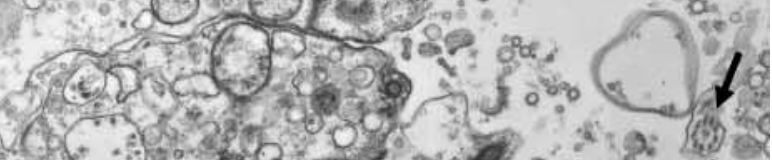

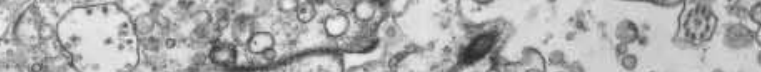

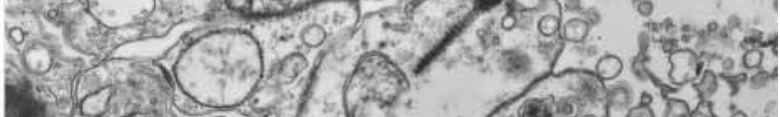
2.
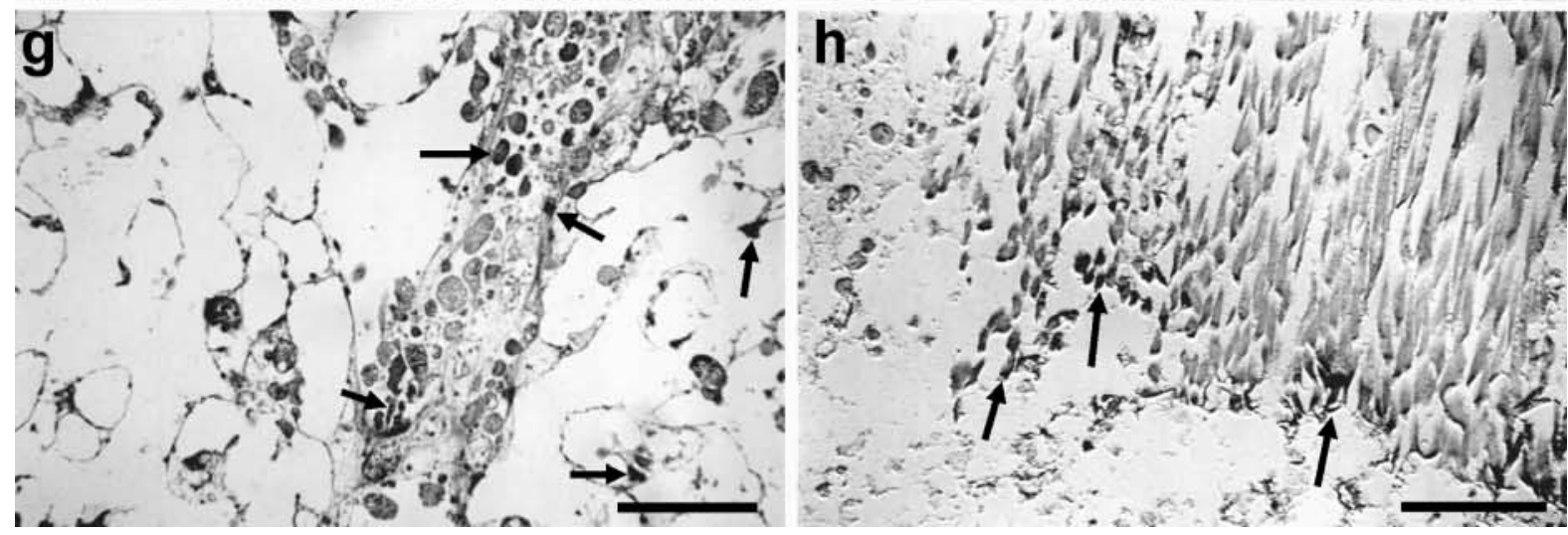
Fig. 5. Antedon mediterranea. Cellular effects of PCB exposure on arm regeneration. (a,b) TEM sections of regenerating arms at $72 \mathrm{~h}$ pa for (a) control, and (b) PCB-exposed specimens. Blastemal cells are detailed. The marked development of RER, Golgi complexes and vacuoles is evident in the PCB-exposed sample (arrow). Scale bars = (a) $1 \mu \mathrm{m}$; (b) $1 \mu \mathrm{m}$. (c,d) TEM sections of PCBexposed regenerating arms at $1 \mathrm{wk}$ pa. Detail shows abundant lipid inclusions (arrows) (c) at the level of phagocytes, still unusually present in the apical blastema of this stage, and (d) at the level of the regenerating axonal ends of the brachial nerve. Scale bars $=$ (c) $2 \mu m_{i}$ (d) $2 \mu \mathrm{m}$. (e,f) TEM longitudinal sections of PCB-exposed regenerating arms at 1 wk pa. Details of the regenerates at the level of the coelothelium (e) and the ambulacral epithelium (f). Both the epithelia show advanced differentiation and rather normal features. Arrows, flagella. (e) Scale bar $=3 \mu \mathrm{m}_{\text {; }}$ (f) scale bar $=1 \mu \mathrm{m}$. (g,h) LM sagittal sections of PCB-exposed regenerating arms of $2 \mathrm{wk}$. ICC for Cytochrome P450. The details show an intense immunoreaction in many cells (arrows) at the level of the tissues of the stump, particularly in the brachial nerve, in the connective and skeletal tissue $(\mathrm{g})$, and in the peripheral regions of the muscles (h). Scale bars $=(\mathrm{g}) 30 \mu \mathrm{m}$; (h) $30 \mu \mathrm{m}$

between the commercial Aroclor $1260^{\circledR}$ mixture, exposure water and animal tissues (both tissue extracts at the 4 regenerative stages and controls).

Our results provide clear evidence that prolonged exposure to low concentrations of PCBs, typical of moderately polluted coastal zones (Geyer et al. 1994) results in marked bioaccumulation in Antedon mediterranea. This affects mechanisms regulating growth, cell cycle and proliferation, induces modifications in the developmental regenerative processes involving general growth and tissue/cellular anomalies in a similar way to pseudo-endocrine activities which may be related to steroid dysfunction.

During the repair and the early regenerative phases the PCB-exposed samples do not show significant anomalies in terms of general morphology and external anatomy when compared with the controls. During the advanced regenerative phase, however, accelerated growth is clearly evident in the exposed samples and involves both the overall size of the regenerating arm and the differentiation of its typical anatomical structures. A simple statistical analysis carried out on the measured length of the regenerates at 1 and $2 \mathrm{wk}$ confirms that the differences between the exposed and the control samples were particularly significant (Candia Carnevali et al. unpubl.). These effects at the level of general growth and morphology are also associated with unusual features at the level of microscopic anatomy in both the stump and the regenerating arm. The following features of exposed individuals were particularly significant in comparison with those found in control samples: (1) hypertrophy and marked swelling of the coelomic canals; (2) massive and prolonged cellular proliferation/migration involving migratory cells (coelomocytes, amoebocytes, phagocytes, granule-cells; Candia Carnevali et al. 1993, $1995,1997)$ not only at the level of the usual sites of cell recruitment (coelomic epithelium, brachial nerve, apical blastema) but, unexpectedly, also at the level of the muscle bundles of the stump; (3) extensive rearrangement and/or dedifferentiation specifically involving other differentiated tissues of the stump, namely the muscles, the endoskeleton and the connec- tive tissue. In the muscles in particular, individual myocytes seem to undergo progressive dedifferentiation and acquire the features of undifferentiated migrating coelomocytes actively involved in cell division, as shown by BrdU labelling. It is important to emphasize that this was never observed in standard conditions, where regeneration typically employs undifferentiated stem cells. Interestingly, rearrangement/ dedifferentiation during regeneration at the level of the muscles was previously observed in Antedon mediterranea only in the peculiar case of explants. Explants are isolated arm segments able to regenerate independently from their donor arms (Candia Carnevali et al. 1998) and represent an extreme condition, in which regeneration is accomplished by employing alternative mechanisms of cell recruitment comparable to those described for PCB-exposed samples. Thus, when exposed to stress, in terms of either trauma or environmental contamination, the regenerative potential is enhanced and blastemal growth and tissue renewal can involve a partial sacrifice of the muscles which seem to directly provide a significant morphallactic contribution to regeneration in terms of reserve cells. Due to the obvious limitations of the static microscopic approach to a dynamic phenomenon, further studies will be necessary to confirm this hypothesis.

In contrast to that observed in the muscles, rearrangement of connective tissue (both integumental and ligamentous) and the endoskeletal tissue (dermaskeleton) mostly involved extensive degeneration phenomena emphasized by the massive and unusual presence of phagocytes and granule-cells (i.e. elements typically employed in repair processes) even at the advanced regenerative stages. This indicates that the connective tissue is employed as a secondary indirect source of reserve materials for new synthesis rather than producing directly undifferentiated cells for regeneration. The extensive cell proliferation and tissue rearrangement found in the PCB-treated samples seem to confirm that exposure to such ED chemicals significantly affects the regulation of growth by directly interacting with the cascade of cellular processes 
involved in cell cycle and turnover possibly controlled and stimulated, directly or indirectly, by steroid hormones (Marsh \& Walker 1995). Interestingly, in contrast with these phenomena of tissue/cell turnover localised at the stump level, the development/differentiation of tissues and cell lines of the regenerating arm does not show any significant variation with respect to normal regeneration. On the other hand, the unusual ultrastructural features (marked development of endoplasmic reticulum and Golgi complexes, abundant lipid granules and empty vacuoles) shown by many cell types, including the blastemal cells, can possibly be interpreted in the light of activation of cell mechanisms related to steroid synthesis/metabolism (Krstic 1979, Motta 1984) and/or to detoxification processes (Schoenmakers 1980, den Besten 1998). This can possibly be referred to the MO system, which is primarily located in the endoplasmic reticulum (den Besten et al. 1990a, 1993). Data related to the expression of biomarkers that are recognized indicators of possible protective biochemical responses to pollutants, such as mechanisms controlling the levels of free pollutants in the organism or concerning the repair of damage caused by pollutants, are particularly relevant here.

Our ICC results show that in PCB-exposed samples there is an appreciable increase in the expression patterns of specific enzymes such as the microsomal cytochrome P450 monooxygenase system, which are the main enzymes responsible for biotransformation and metabolism of the majority of lipophilic xenobiotics such as PCBs in many vertebrtates and invertebrates, including echinoderms (den Besten 1998). The expression of these factors can be induced in response to a variety of environmental stressors. Since echinoderms are marine deuterostomes closely related to vertebrates, it is not surprising that they show similar induction responses to the same types of xenobiotics. These results clearly reflect toxicant-induced molecular and biochemical aspects of cell physiological alterations and lead us to suggest that exposure to PCBs may induce detoxification processes and related nuclear receptor activities comparable to those known for other invertebrates. The development of specific and direct molecular monitoring methods for exploring endocrine-disrupter induced modulations of nuclear receptor activities in echinoderms will be a useful tool to throw light on these points.

In conclusion, the regenerative response of crinoid echinoderms represents a sensitive test for contamination by endocrine disrupter pollutants and provides an important indication of both unexpected sublethal effects and mechanisms of toxicity of such compounds with respect to those previously known (Colborn \& Clement 1992, Fairley et al. 1996, Grey et al. 1996).
Acknowledgements. The present work has received financial support from: (1) Italian National Research Concil (CNR Project: Biotechnology; Sub-project: Environmental Biotechnology); (2) MURST Research Project; (3) British Council AngloItalian exchange scheme; and (4) University of London and Royal Holloway Research Funds.

\section{LITERATURE CITED}

Aminin DL, Agafonova IG, Fedorov SN (1995) Biological activity of disulfated polyhydroxysteroids from the Pacific brittle star Ophiopholis aculeata. Comp Biochem Physiol C 112:201-204

Anderson S, Hose JE, Knezovich JP (1994) Genotoxic and developmental effects in sea urchin are sensitive indicators of effects genotoxic chemicals. Environ Toxicol Chem 13:1033-1041

Ballschmiter K, Zell M (1980) Analysis of polychlorinated biphenyls (PCBs) by glass capillary gas chromatography: composition of technical Aroclor ${ }^{\circledR}$ and Clophen-PCB mixtures. Fresenius Z Anal Chem 302:201-231

Candia Carnevali MD, Lucca E, Bonasoro F (1993) Mechanism of arm regeneration in the feather star Antedon mediterranea: healing of wound and early stages of development. J Exp Zool 267:299-317

Candia Carnevali MD, Bonasoro F, Lucca E, Thorndyke MC (1995) Pattern of cell proliferation in the feather star Antedon mediterranea. J Exp Zool 272:464-474

Candia Carnevali MD, Bonasoro F, Invernizzi R, Lucca E, Welsch U, Thorndyke MC (1996) Tissue distribution of monoamine neurotransmitters in normal and regenerating arms of the feather star Antedon mediterranea. Cell Tissue Res 285:341-352

Candia Carnevali MD, Bonasoro F, Biale A (1997) Pattern of bromodeoxyuridine incorporation in the advanced stages of arm regeneration in the feather star Antedon mediterranea. Cell Tissue Res 289:363-374

Candia Carnevali MD, Bonasoro F, Patruno M, Thorndyke MC (1998) Cellular and molecular mechanisms of arm regeneration in crinoid echinoderms: the potential of the arm explants. Dev Genes Evol 208:421-430

Candia Carnevali MD, Galassi S, Bonasoro F, Dina G, Terlizzi MA, Patruno M, Thorndyke MC (1999) PCB-induced environmental stress and the regenerative response in crinoids. In: Candia Carnevali MD, Bonasoro F (eds) Echinoderm research 1998. Balkema, Rotterdam, p 471-476

Clark AH (1921) A monograph of the existing crinoids. Bull US Nation Mus 82, Vol 1. The comatulids, Part 1

Colborn T, Clement C (1992) Chemically induced alterations in sexual and functional development: the wildlife/human connection. Princeton Scientific Publishing, Princeton, NJ

Connell DW (1990) Bioaccumulation of xenobiotic compounds. CRC Press, Boca Raton, FL

Cooper RL, Kavlock RJ (1997) Endocrine disruptors and reproductive development: a weight-of-evidence overview. J Endocrinol 152:159-166

den Besten PJ (1998) Cytochrome P450 monooxygenase system in echinoderms. Comp Biochem Physiol C 121:139-146

den Besten PJ, Herwig HJ, Zandee DI, Voogt PA (1989) Effects of Cadmium and PCBs on reproduction of the sea star Asterias rubens: aberrations in the early development. Ecotoxicol Environ Saf 18:173-180

den Besten PJ, Herwig HJ, van Donselaar EG, Livingstone DR (1990a) Cytochrome P-450 monooxygenase system and benzo[a]pyrene metabolism in echinoderms. Mar Biol 107: $171-177$ 
den Besten PJ, Herwig HJ, Smaal AC, Zandee DI, Voogt PA (1990b) Interference of polychlorinated biphenyls (Clophen A50) with gametogenesis in the sea star Asteria rubens L. Aquat Toxicol 28:231-246

den Besten PJ, Elenbaas JML, Maas EJR, Dieleman SJ, Herwig HJ, Voogt PA (1991) Effects of cadmium and polychlorinated biphenyls (Clophen A50) on steroid metabolism and cytochrome p-450 monooxigenase system in the sea star Asterias rubens L. Aquat Toxicol 20:95-100

den Besten PJ, Lemaire P, Livingstone DR, Woodin B (1993) Time-course and dose response of the apparent induction of the cytochrome P-450 monooxygenase system of pyloric caeca microsome of the female sea star Asterias rubens L. by benzo[a]pyrene and polychlorinated biphenyls. Aquat Toxicol 26:23-40

Fairley P, Roberts M, Stringer J (1996) Endocrine disruptor. Chem Week May 8:29-36

Galassi S, Guzzella L, De Paolis A (1993) PCB levels in sediments of the Adriatic sea. Fresenius Environ Bull 2: 25-30

Galassi S, Valsecchi S, Tartari GA (1997) The distribution of PCBs and chlorinated pesticides in two connected Himalayan lakes. Water Air Soil Pollut 99:717-725

Geyer H, Freitag D, Korte F (1994) Polychlorinated biphenyls (PCBs) in the marine environment, particularly in the Mediterranean. Ecotoxicol Environ Saf 8:129-151

Gillesby BE, Zacharewki TR (1998) Exoestrogens: mechanism of action and strategies for identification and assessment. Environ Toxicol Chem 17:3-14

Golub M, Donald J, Reyes J (1991) Reproductive toxicity of commercial PCB mixtures: LOAELS and NOAELS from animal studies. Environ Health Perspect 94:245-253

Gould JC, Cooper KR, Scanes CG (1997) Effects of polychlorinated biphenyl mixtures and three specific congeners on growth and circulating growth-related hormones. Gen Comp Endocrinol 106:221-230

Gray LE Jr, Monosson E, Kelce WR (1996) Emerging issues: the effects of endocrine disrupters on reproductive development. In: Di Giulio RT, Monosson E (eds) Interconnection between human and ecosystem health. Chapman \& Hall, London, p 47-81

Hawker DW, Connell DW (1988) Octanol-water partition coefficients of polychlorinated byphenyl congeners. Environ Sci Technol 22:382-387

Hinton DE (1997) Histologic responses signifying exposure or effect and their application to aquatic ecotoxicology. In: Zelikoff JT (ed) Ecotoxicology: responses, biomarkers and risk assessment. An OECD workshop, SOS Publication, Fair Haven, NY, p 293-309

Krstic RV (1979) Ultrastructure of the mammalian cell. An atlas. Springer-Verlag, Berlin

Landrum PF, Crosby DG (1981) Comparison of the disposition of several nitrogen-containing compounds in the sea urchin and other marine invertebrates. Xenobiotica 11: 351-361

Lake JL, McKinney R, Lake CA, Osterman FA, Heltshe J (1995) Comparison of patterns of polychlorinated biphenyl congeners in water, sediment, and indigenous organisms from New Bedford Harbor, MA. Arch Environ Contam Toxicol 29:207-220

Malins DC, Roubal WT (1982) Aryl sulfate formate formation in sea urchins (Strongylocentrotus droebachiensis) ingesting marine algae (Fucus distichus) containing 2,6dimethylnaphthalene. Environ Res 27:290-297

Marks TA, Kimmel GL, Staples RF (1989) Influence of symmetrical polychlorinated biphenyl isomers on embryo and fetal development in mice. Fundam Appl Toxicol 13: 681-693

Marsh A, Walker C (1995) Effect of estradiol and progesterone on $c-m y c$ expression in the sea star testis and the seasonal regulation of spermatogenesis. Mol Reprod Dev 40:62-68

Mercier A, Pelletier E, Hamel JF (1994) Metabolism and subtle effects of butyltin compounds in starfish. Aquat Toxicol 28:259-273

Meyer T, Bakke T (1977) The metabolism of biphenyl. V. Phenolic metabolites in some marine organisms. Acta Pharmacol Toxicol 40:201-208

Motta PA (1984) Ultrastructure of endocrine cells and tissues. Series in electron microscopy, Vol 1. Nijhoff M Publishers, The Hague

Picer M, Picer N (1991) Levels and long-term trends of some high molecular chlorinated hydrocarbons in mussels collected from the western Istrian coastal waters - Northern Adriatic. Chemosphere 23:747-759

Provini A, Galassi S (1999) Polychlorinated biphenyls and chlorinated pesticides in bird eggs from Calabria (Southern Italy). Ecotoxicol Environ Saf 43:91-97

Reichensperger A (1912) Beiträge zur Histologie und zum Verlauf der Regeneration bei Crinoiden. Z Wiss Zool 101: 1-69

Shirai H, Walker CW (1988) Chemical control of asexual and sexual reproduction in echinoderms. Alan R Liss Inc, New York

Schoenmakers HJN (1979) In vitro biosynthesis of steroids from cholesterol by the ovaries and pyloric caeca of the starfish Asterias rubens. Comp Biochem Physiol B 63:179-184

Schoenmakers HJN (1980) The variation of $3 \beta$-hydroxysteroid dehydrogenase activity of the ovaries and pyloric caeca of the starfish Asterias rubens during the annual reproductive cycle. J Comp Physiol 138:27-30

Schweitzer LE, Hose JL, Suffet IH, Bay SM (1997) Differential toxicity of three polychlorinated biphenyl congeners in developing sea urchin embryos. Environ Toxicol Chem 16: 1510-1514

Shubina LK, Fedorov SN, Levina EV, Andriyaschenko PV, Kalinovsky AI, Stonik VA, Smirnov IS (1998) Comparative study on polyhydroxylated steroids from echinoderms. Comp Biochem Physiol B 119:505-511

Thorndyke MC, Chen WC, Moss C, Candia Carnevali MD, Bonasoro F (1999) Regeneration in echinoderms: cellular and molecular aspects. In: Candia Carnevali MD, Bonasoro F (eds) Echinoderm research 1998. Balkema, Rotterdam, p 159-164

Thorndyke MC, Candia Carnevali MD (2001) Regeneration, neurohormones and growth factors in echinoderms. Can J Zool (in press)

Voogt PA, Oudejans RCHM, Broertjes JJS (1984) Steroids and reproduction in starfish. In: Engels W, Clark WH, Fischer A, Olive PJW, Went DF (eds) Advances in invertebrate reproduction. Elsevier North-Holland Inc, New York, p 151-161

Voogt PA, de Wells D, Reutergardh L, Brinkman UATH (1990) Biological activity, determination and occurrence of planar, mono and di-ortho polychlorinated biphenyls. Int J Environ Anal Chem 40:1-46

Voogt PA, den Besten PJ, Jansen M (1991) Steroid metabolism in relation to the reproductive cycle in Asterias rubens L. Comp Biochem Physiol B 99:77-82

Wania F, Mackay D (1993) Global fractionation and cold condensation of low volatility organochlorine compounds in polar regions. Ambio 22:10-18

Submitted: September 12, 1999; Accepted: August 16, 2000 Proofs received from author(s): May 18, 2001 